\title{
Synthesis of $\mathrm{RuO}_{2}$ Nanowires by Alkali-Assisted
}

\section{Oxidation of Ruthenium in Plasma Afterglow at}

\section{Atmospheric Pressure}

\author{
D. Kuete Saa, T. Gries, S. Migot-Choux, J. Ghanbaja, P. Boulet, S. Laminsi, T. Belmonte
}

\begin{abstract}
RuO}_{2}$ nanowires are synthesized by oxidation of ruthenium thanks to a micro-post-discharge at atmospheric pressure. However, $\mathrm{RuO}_{2}$ nanowires form islands. The growth mechanism depending on surface defects, the surface density of the nanowires is limited. We report on the influence of two alkali salts, $\mathrm{NaCl}$ and $\mathrm{KCl}$, deposited as grains on ruthenium to act as defects and increase the nanowire density. These grains induce the growth of $\mathrm{RuO}_{2}$ nanowires all around them, creating a circular area where nanowires are found. Nanowires start growing at the triple point at the grain base where the alkali-salt grain, ruthenium from the substrate and oxidizing gaseous species coexist. When nanowires grow, the stress induced in the surrounding layer creates new cracks, making possible the radial propagation of the nanowires. The presence of nanowires on grains is due to the etching mechanism that converts the alkali salt into an oxide, enabling onward oxidation of ruthenium.
\end{abstract}

Index terms - Ruthenium oxide, nanowires, plasma oxidation, afterglow, atmospheric pressure

\section{INTRODUCTION}

L OW PRESSURE plasmas are known to be fast processes to synthesize one-dimensional nanostructures [1-6]. The importance of ion bombardment on the anisotropic growth of these objects is crucial. At atmospheric pressure, ion bombardment being negligible, other strategies have to be developed in order to get high growth rates.

The group of M. K. Sunkara proposed several methods $[1,7]$ to achieve this goal. One way of synthesizing metal oxide nanowires at ultrahigh rates (on the scale of a minute) [8-11] relies on the combination of a transition metal or a transition metal oxide with an alkali salt, like $\mathrm{NaCl}$ or $\mathrm{KCl}$, to produce a mixture which is treated by a plasma at atmospheric pressure. This process mimics somehow the hydrothermal synthesis technique.

A high contact surface between the metal and alkali particles is mandatory. This can be achieved either by sprinkling alkali

Manuscript received Month Day, YEAR; revised Month Day, YEAR; accepted Month Day, YEAR.

D. Kuete Saa, T. Gries, S. Migot-Choux, J. Ghanbaja, P. Boulet and T. Belmonte are with the CNRS and the Universite de Lorraine, Institut Jean Lamour, UMR CNRS 7198, NANCY, F-54042, France. (e-mail: thierry.belmonte@univ-lorraine.fr)

D. Kuete Saa and S. Laminsi are with the Université de Yaoundé 1, Laboratoire de Chimie Physique et Analytique Appliquées, 812 Yaoundé, Cameroon.

Copyright (c) 2015 IEEE. Personal use of this material is permitted. However, permission to use this material for any other purposes must be obtained from the IEEE by sending a request to pubs-permissions@ieee.org

Digital Object Identifier 10.1109/TNANO.2017.XXXXXXX particles on a metal foil or by mixing intimately alkali and metal powders. Like this, an alkali metal metallate is synthesized. Next, this compound must be purified by dipping in an $\mathrm{HCl}$ solution (substitution of the alkali in the metallate by hydrogen) and either annealed or exposed to oxygen plasma (removal of hydrogen).

Basically, the role of the plasma in this alkali-assisted process is simply practical, the plasma acting as a heat source. Indeed, $\mathrm{O}_{2}$ in its neutral state is proposed to be the main oxidizing species. This conclusion is consistent with the high synthesis temperature, which is close to $1273 \mathrm{~K}$ in this process.

In this work, the strategy proposed by the group of M. K. Sunkara is applied to a ruthenium substrate covered by $\mathrm{NaCl}$ or $\mathrm{KCl}$ grains. Indeed, ruthenium dioxide $\mathrm{RuO}_{2}$ is a key material for supercapacitors [12-14] in which it has to be present with the highest possible specific surface area to store electrons.

Music et al. [15] demonstrated from the suggestion by Lin et al. [16] that the presence of the gaseous hyperoxide $\mathrm{RuO}_{3}$ is relevant for the formation of nanorods. Lin et al. [16] showed that $\mathrm{RuO}_{2}$ was deposited by reactive sputtering of ruthenium in an oxidizing atmosphere as a relatively smooth film at 473 $\mathrm{K}$, then as a pile of short rods at $573 \mathrm{~K}$, and finally as perfectly faceted nanorods at $723 \mathrm{~K}$. According to Hsu et al. [17], although ruthenium etching in ICP plasmas correlates well with the oxygen radical density, chlorine-containing species also play a role.

In a previous work [18], we showed that the synthesis of $\mathrm{RuO}_{2}$ nanowires was possible by oxidation with an atmospheric microwave micro-afterglow on a ruthenium substrate. The use of a non-equilibrium medium allows a lowering of the temperature in respect of thermal oxidation, given that molecular oxygen is excited or dissociated, which provides more reactive species such as singlet oxygen $\mathrm{O}_{2}\left(\mathrm{a}^{1} \Delta_{\mathrm{g}}\right)$ or atomic oxygen. This improves the anisotropy of growth, and then, the synthesis of nanowires.

In these specific conditions, ruthenium oxidation produces a general nanostructure made of lamellae spaced 20-50 nm apart within a temperature range of $[530 \mathrm{~K}-820 \mathrm{~K}]$. Spread over the surface, localized bundles of nanowires are formed with an occurrence that depends on the temperature. The growth mechanism of the localized bundles is driven by stress from emerging defects, as explained in one of our former works on 
silicon oxidation by the same process $[19,20]$. Oxidation of ruthenium was proposed to proceed this way:

$$
\mathrm{Ru}^{4+}+4 \mathrm{e}^{-}+\left(2 \mathrm{O} \text { or } \mathrm{O}_{2}{ }^{*}\right) \rightarrow \mathrm{RuO}_{2}
$$

Metals with "valve" native oxides, i.e. dense oxides that stop diffusional processes like $\mathrm{SiO}_{2}, \mathrm{ZrO}_{2}$ or $\mathrm{RuO}_{2}$, get oxidized by forming these bundles where surface defects act as weak points enabling diffusion.

In this work, we choose to introduce voluntarily "defects" in a controlled manner by depositing on the surface of ruthenium, micro-grains of alkali salts to serve as preferential sites for the growth of nanowires. The idea is to enhance the surface density of $\mathrm{RuO}_{2}$ nanowires, salts being next easily removed by dissolution in water. A special attention will be paid to the growth mechanism of the nanowires.

\section{EXPERIMENTAL SET-UP}

The experimental set-up is shown in Fig. 1. An atmospheric Ar- $\mathrm{O}_{2}$ microwave plasma is ignited in a fused silica tube (27 $\mathrm{mm}$ inner diameter) placed in a $2.45 \mathrm{GHz}$ resonant cavity. The power absorbed by the plasma is $100 \mathrm{~W}$. Flow rates of gases are controlled by two mass flow controllers and the total flow rate is $825 \mathrm{sccm}$ (standard cubic centimeter per minute). The partial pressure of oxygen in the gas mixture is set at 7.5 vol.\%. The treatment time is 2 hours. The micro-afterglow is visible as a light beam escaping a hole $(600 \mu \mathrm{m}$ in diameter $)$ drilled in a brass plate screwed on one wall of the cavity [14]. Light emission is due to NO radiative species produced by reaction between oxidizing active species in the afterglow and nitrogen from the ambient air. These species are mainly $\mathrm{O}$, $\mathrm{O}_{2}$ (a) and $\mathrm{O}_{2}(\mathrm{X})$ because the afterglow is too hot to produce $\mathrm{O}_{3}$ (typically, the rotational temperature of $\mathrm{OH}$ molecules due to the water flux from the surrounding air - determined by optical emission spectroscopy in the present conditions is $\sim 1000 \mathrm{~K}$ at the nozzle exit [14]). However, far enough from the beam (and then from the treated spot on the substrate surface), $\mathrm{O}_{3}$ can be detected.
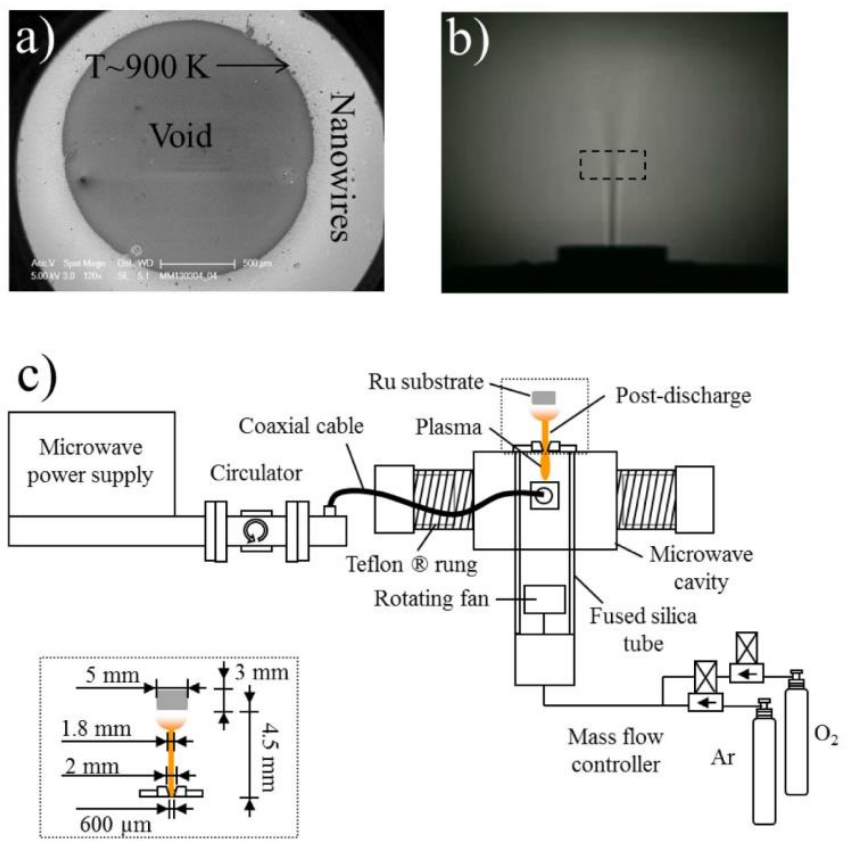

Fig. 1. a) Transition at $900 \mathrm{~K}$ between the void and the nanowire outer ring (in this example, a silicon wafer coated by a $1 \mu$ m-thick $\mathrm{RuO}_{2}$ PVD coating is used as sample). b) Shadowgraphy image of the afterglow beam. The position of the ruthenium substrate is depicted by the dotted line. c) The experimental set-up.
Samples are cuboids $\left(5 \times 5 \times 3 \mathrm{~mm}^{3}\right)$ of high purity metallic ruthenium (99.99\%). They are polished mechanically (final stage $1 \mu \mathrm{m}$ diamond paste), ultrasonically cleaned in acetone and rinsed with ethanol before treatment. The sample-nozzle distance is set at $4.5 \mathrm{~mm}$.

$\mathrm{NaCl}$ and $\mathrm{KCl}$ are used as alkali sources. They are dissolved in water at different concentrations $(0.04,0.08$ and $0.16 \mathrm{~g}$ $\left.\mathrm{mL}^{-1}\right)$. Next, the ruthenium substrate is spin-coated by a solution of that type and water is evaporated in the air at room temperature. This gives large grains of alkali salts on the surface, ranging typically from $5 \mu \mathrm{m}$ to $20 \mu \mathrm{m}$ in diameter. The wettability of the solution on ruthenium is about $70^{\circ}$. Another procedure was applied to enhance the surface coverage by smaller grains. The ruthenium samples are pretreated in a low pressure nitrogen afterglow to decrease the wettability (conditions: pressure: 1 mbar, microwave power: $100 \mathrm{~W}$, gas mixture: $\operatorname{Ar}(500 \mathrm{sccm})-\mathrm{N}_{2}(100 \mathrm{sccm})$, distance from gap: $1 \mathrm{~m}$, processing temperature: $320 \mathrm{~K}$, treatment duration: $10 \mathrm{~min}$ ). The sample is spin-coated by the solution and put under primary vacuum (1 mbar) to evaporate the water much faster to limit coarsening and get smaller size distribution of alkali salt grains. In this case, grains are found aligned along surface scratches with mean diameters inferior to $5 \mu \mathrm{m}$ and the wettability of solution is around $30^{\circ}$.

An important aspect of micro-afterglow treatment deals with the radial temperature distribution on the sample surface. Although ruthenium tetroxide $\mathrm{RuO}_{4}$ sublimes at $313 \mathrm{~K}$, it can be synthesized as solid above this temperature. Starting from pure ruthenium, and only in this condition, oxidation below $473 \mathrm{~K}$ produces solid $\mathrm{RuO}_{2}$ and solid $\mathrm{RuO}_{3}$ [16]. This latter oxide can be further oxidized into solid $\mathrm{RuO}_{4}$ between 523 and $573 \mathrm{~K}$ [16]. In the present work, ruthenium is always covered by a $\mathrm{RuO}_{2}$ passive layer. Consequently, ruthenium tetroxide being gaseous above $900 \mathrm{~K}[17,19]$, the hottest part of the surface hit by the afterglow beam is continuously evaporated and cannot support any nanowire growth. Gaseous $\mathrm{RuO}_{3}$ is emitted at slightly higher temperature $(\sim 1000 \mathrm{~K}$ after [17]). If the sample is large and thick enough to create thermal gradients, this phenomenon leads to the formation of a void with a diameter where the temperature is higher than $900 \mathrm{~K}$ (see Fig. 1a).

In the present conditions, we demonstrated that the size of the samples do not allow any significant temperature gradient (below $4 \mathrm{~K}$ ) in the whole volume of these small $\left(5 \times 5 \times 3 \mathrm{~mm}^{3}\right)$ metallic cuboids [18]. Because no void was ever observed in the present treatments, the surface temperature was always below $900 \mathrm{~K}$. It was estimated to be $570 \pm 20 \mathrm{~K}$ [18].

Treated surfaces were characterized by Scanning Electron Microscopy (SEM), X-Ray Diffraction (XRD) and Transmission Electron Microscopy (TEM). X-ray measurement were performed with a Bruker D8 Diffractometer using a point focus beam and the CoK $\alpha$ wavelengh $(\lambda=0.179026 \mathrm{~nm})$

\section{RESULTS AND DISCUSSION}

Without alkali salts, afterglow oxidation of ruthenium produces a general nanostructure made of lamellae spaced 20$50 \mathrm{~nm}$ apart within a temperature range of $[530 \mathrm{~K}-820 \mathrm{~K}]$ [18]. Spread over the surface, sea-urchin-like localized objects made of concentric rings of nanowires are formed with an occurrence that depends on the temperature. Their growth is driven by stress from emerging defects $[18,20]$. An emerging dislocation, for instance, acts as a preferential path to transport ruthenium from the substrate core to the surface. Injection of interstitial metallic ions certainly occurs at the inner interface. 
The nanowire grows by outward diffusion of ruthenium. Oxygen atoms feed directly the nanowire. These atomic species, readily available in afterglow - because no dissociation of molecular oxygen is needed - are required at very low temperature. The outward diffusion of silicon is balanced by the inward diffusion of vacancies. Their agglomeration creates Kirkendall porosity at the inner interface and this phenomenon can eventually limit the growth. When the nanowire grows, it induces a radial stress field in the passive oxide layer until new defects appear at the surface, close to it. A new nanowire starts growing and the process perpetuates gradually, forming sea-urchin-like structures.

\section{A. Nanowires morphology}

When $\mathrm{NaCl}$ grains are sprinkled on ruthenium, they create preferential local active sites to initiate the nanowires growth. Crystalline grains exhibit well-faceted shapes with sharp edges (see supplemental material 1). In Fig. 2, we observe the formation of nanowires on $\mathrm{NaCl}$ grains from the afterglow center outwards (up to $2.5 \mathrm{~mm}$ ) after a two-hour treatment. These grains are, most often, the centers of circular areas in which nanowires are found. By comparison with results from our former work [18], the surface density of these areas increases by a factor of 17 (from $1 \times 10^{4} \mathrm{~cm}^{-2}$ to $17 \times 10^{4} \mathrm{~cm}^{-2}$ for a 2-hour treatment), areas having similar diameters in both cases. They lie between $2 \mu \mathrm{m}$ and $23 \mu \mathrm{m}$ without $\mathrm{NaCl}$ and between $3 \mu \mathrm{m}$ and $35 \mu \mathrm{m}$ with $\mathrm{NaCl}$.
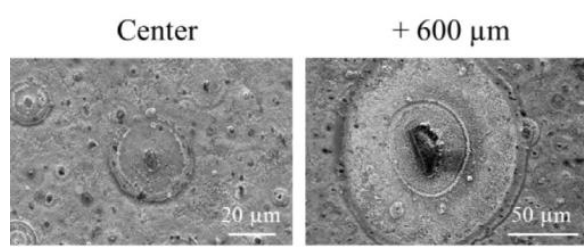
$+1000 \mu \mathrm{m}$
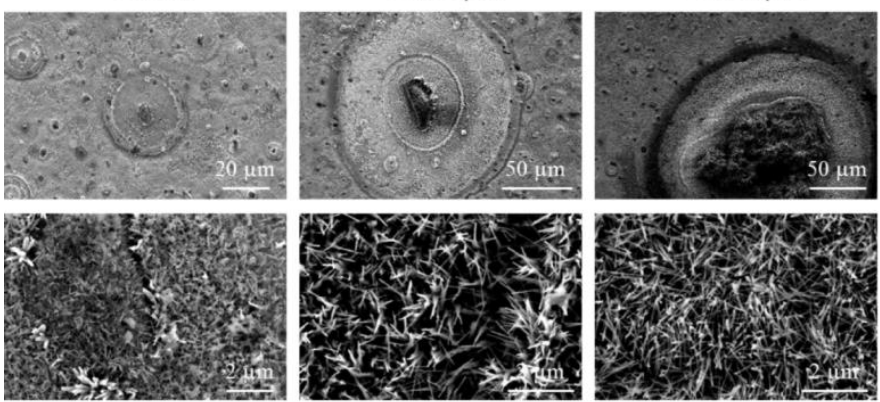

$+2100 \mu \mathrm{m}$
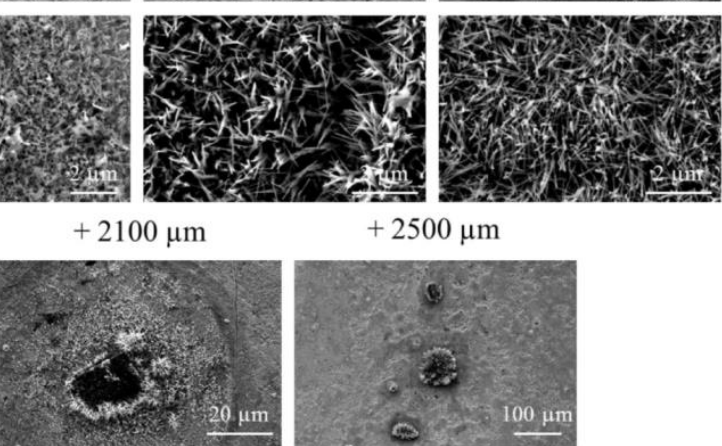

$+2500 \mu \mathrm{m}$
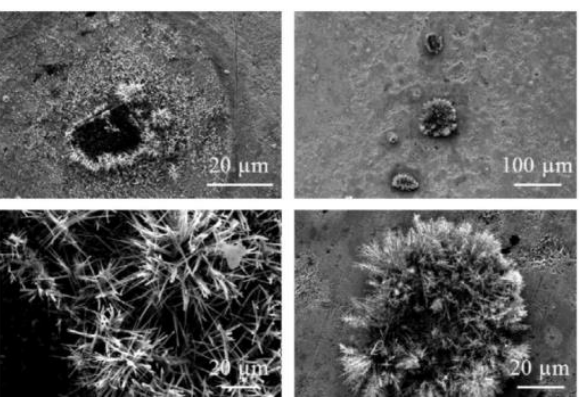

Fig. 2. Radial evolution of nanowire shapes on $\mathrm{NaCl}$ grains $\left(0.16 \mathrm{~g} \mathrm{~mL}^{-1}\right)$.

The radial evolution of nanowires exhibits similar features with $\mathrm{KCl}$ instead of $\mathrm{NaCl}$ (Fig. 3). The most striking difference lies in the shape of the nanowires which is much thicker (their diameter varies from $\sim 500 \mathrm{~nm}$ to $\sim 2 \mu \mathrm{m}$ while the diameter of nanowires obtained in the presence of $\mathrm{NaCl}$ is $\sim 200 \mathrm{~nm}$ ). Another interesting feature of $\mathrm{KCl}$ grains is their complete capping by nanowires, whatever their size. $\mathrm{NaCl}$ grains are most often only decorated on edges, even though the smallest grains can be completely capped by nanowires.

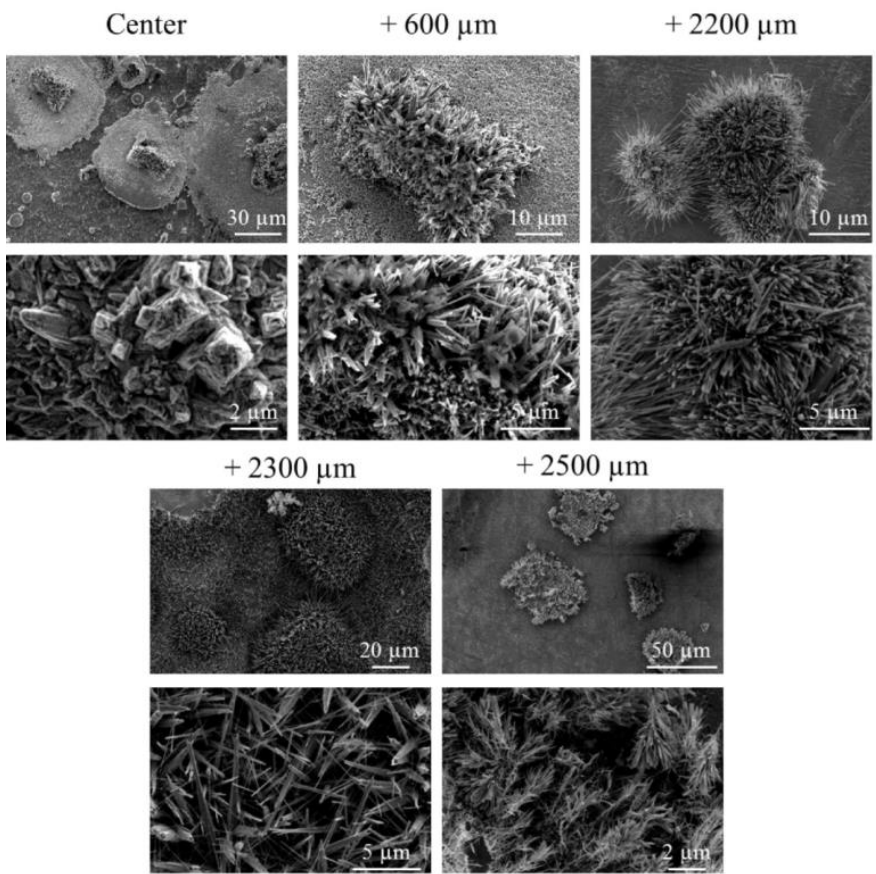

Fig. 3. Radial evolution of nanowire shapes on $\mathrm{KCl}$ grains $\left(0.04 \mathrm{~g} \mathrm{~mL}^{-1}\right)$.

In Fig. 4, we can observe how bundles of nanowires grow around $\mathrm{NaCl}$ grains.
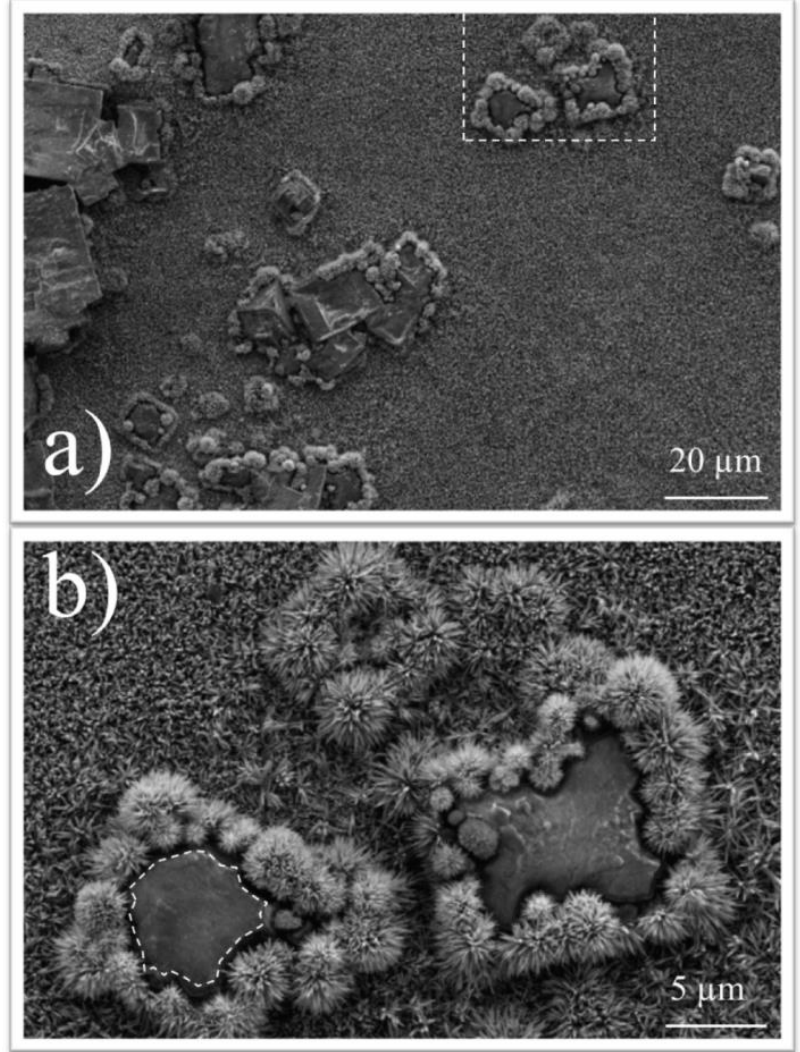

Fig. 4. a) Large view image of bundles of nanowires grown around $\mathrm{NaCl}$ grains (same experimental conditions as usually. Sharp edges without nanowires are clearly visible. b) Magnification of the dotted frame showing bundles of nanowires around two $\mathrm{NaCl}$ grains with etched edges. Each bundle corresponds to a serration in the grain.

These crystalline grains exhibit sharp edges before the appearance of nanowires (Fig. 4a). When nanowires start growing, they form bundles attached to grain edges. Patently, 
edges are etched and adopt locally the curvature radii of the bundles (Fig. 4b). When the grain height is high, nanowires appear only at the base of the grain (Fig. 4a). If the grain is small enough, both in height and in size, it can be completely converted (Fig. 4b). Consequently, the longest nanowires are found at the triple point where $\mathrm{NaCl}, \mathrm{Ru}$ from the substrate and oxidizing gaseous species are simultaneously found, i.e. the boundary of square that defines the $\mathrm{NaCl}$ or $\mathrm{KCl}$ grain base. The fact that only the small grains of $\mathrm{NaCl}$ are covered by nanowires results from the overlapping of nanowire bundles growing from opposite sides. This is readily observed in Fig. 4b (grain at the top of the image, for example).In Fig. 5 , we observe that nanowires can also grow between grains. We explained previously that it was possible to grow these nanowires without alkali salts [18]. Then, when grains are sprinkled on ruthenium, the growth of nanowires between these grains is generally observed far from the center, at the edge of the sample, on the coldest areas. The growth from emerging surface defects is always possible in our conditions but the growth from grain edges requires a minimum temperature.
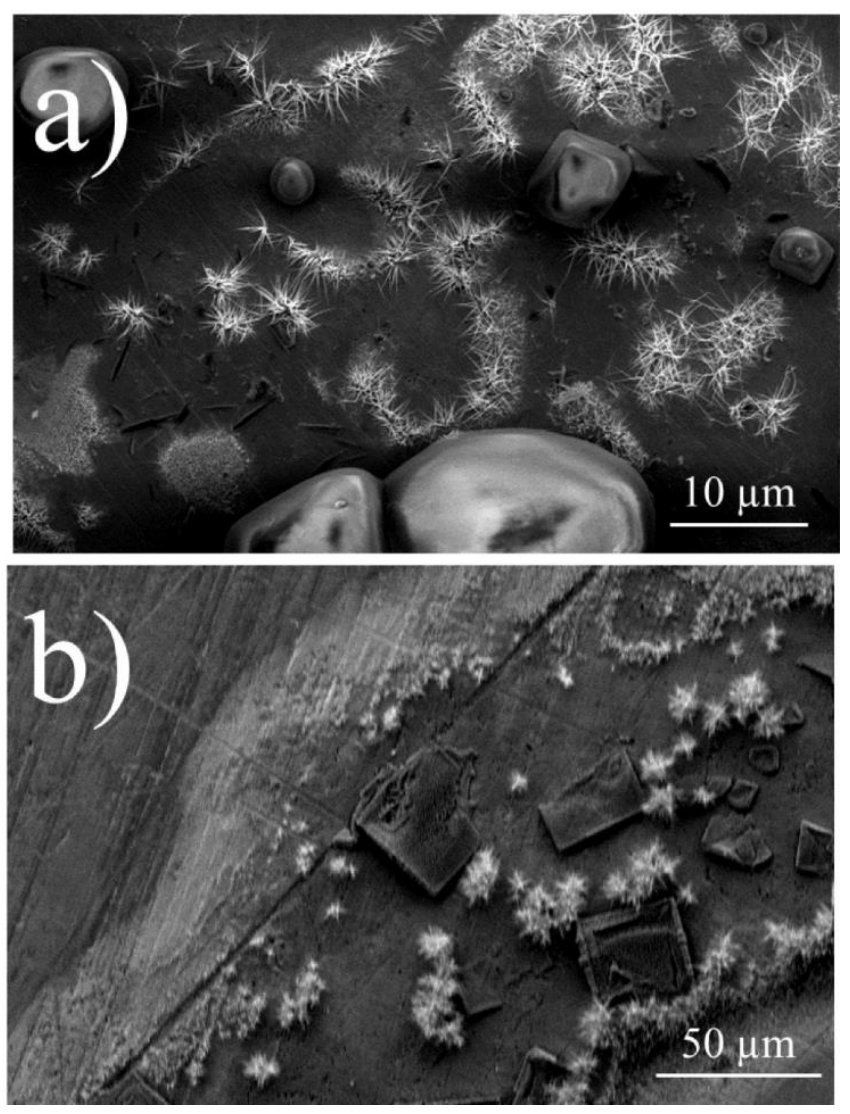

Fig. 5. a) Example of nanowires grown around $\mathrm{NaCl}$ grains. b) Idem around $\mathrm{KCl}$ grains.

\section{B. Influence of Salt Concentration}

When different concentrations of alkali chloride solutions are deposited, the surface density of grains increases with the concentration. The grain size varies from $1-2 \mu \mathrm{m}$ to $2-3 \mu \mathrm{m}$ and to $4-5 \mu \mathrm{m}$ for a concentration increasing from 0.04 to 0.08 $\mathrm{g} \mathrm{mL}^{-1}$ and to $0.16 \mathrm{~g} \mathrm{~mL}^{-1}$. This general behavior is also found with $\mathrm{KCl}$ grains. However, within these ranges of concentration, no significant modifications of the nanowires features were observed around one isolated grain. Tests with even higher concentrations showed that if a too thick layer of salt is deposited, no nanowires could be grown.

\section{X-ray Analysis}

X-ray measurements were performed at grazing incidence for two reasons: on one hand, the layer of oxide is thin, and the grains of $\mathrm{NaCl}$ are relatively small (of the order of one micrometer) and of moderate density on the other hand Measurements at grazing incidence ( $4^{\circ}$ in our case) are thus required to increase the ratio of the probed volumes of $\mathrm{RuO}_{2}$ to $\mathrm{Ru}$. Fig. 6 shows respectively XRD patterns of a pure ruthenium substrate $(\mathrm{Ru})$, a ruthenium substrate covered by $\mathrm{NaCl}$ grains $(\mathrm{Ru}+\mathrm{NaCl})$ and a ruthenium substrate covered by $\mathrm{NaCl}$ and oxidized by micro-afterglow $\left(\mathrm{Ru}+\mathrm{NaCl}+\mathrm{RuO}_{2}\right)$. The analysis performed on $\mathrm{Ru}+\mathrm{NaCl}$ shows, besides the peaks of the substrate, those of sodium chloride. $\mathrm{NaCl}$ peaks are identified respectively at $2 \theta=37.3^{\circ}(200)$, at $2 \theta=53.1^{\circ}(220)$, at $2 \theta=66.6^{\circ}(222)$ at $2 \theta=90.6^{\circ}(420)$ and $2 \theta=102.1^{\circ}(422)$. When the spectrum obtained after oxidation by microafterglow $\left(\mathrm{Ru}+\mathrm{NaCl}+\mathrm{RuO}_{2}\right)$ is superimposed on the spectra of $\mathrm{Ru}$ and $\mathrm{Ru}+\mathrm{NaCl}$, there appear new peaks which are assigned to ruthenium dioxide $\left(\mathrm{RuO}_{2}\right)$. Among these peaks, we can note the following peaks: (110), (101) and (211) respectively at $2 \theta$ $=33.3^{\circ}, 2 \theta=41.5^{\circ}$ and $2 \theta=64.4^{\circ}$. No other phase is observed.

Identical conclusions are drawn if the alkali salt is potassium chloride (see supplemental material 2).

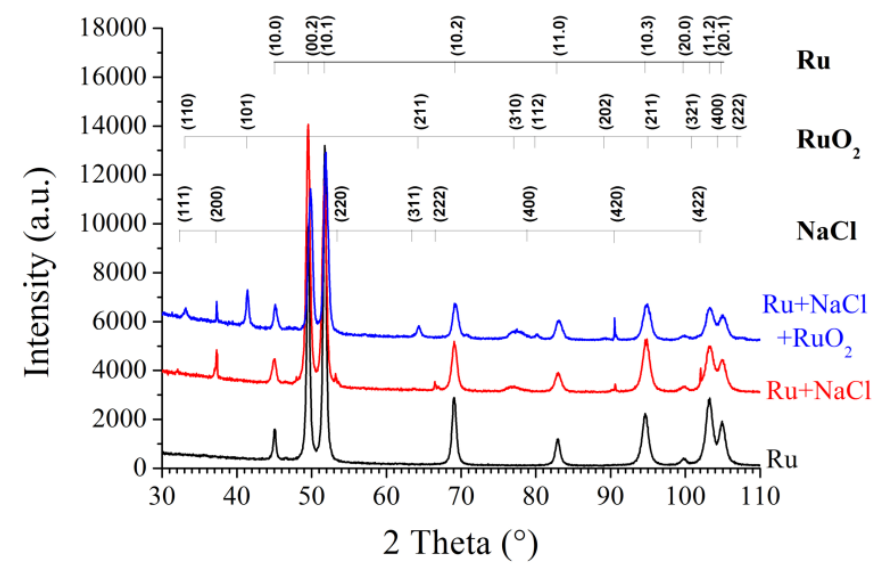

Fig. 6. X-ray patterns $\left(\lambda_{\mathrm{CoK} \alpha}\right)$ of ruthenium sample (black), of ruthenium substrate covered by $\mathrm{NaCl}$ grains (red) and of ruthenium substrate covered by $\mathrm{NaCl}$ and which was oxidized by micro-afterglow plasma (blue).

\section{Nanowires crystalline structure}

TEM analyses of nanowires grown with $\mathrm{NaCl}$ show that two types of nanowires are synthesized: feather-like nanostructures and single or bi-crystal nanowires (Fig. 7). Micro-diffraction analyses indicate that both types of nanowires can be indexed by $\mathrm{RuO}_{2}$ (rutile $\mathrm{P}_{2} / \mathrm{mnm} ; a=4.4919 \AA ; c=3.1066 \AA$ ).

Fast Fourier Transform (FFT) analysis applied to highresolution TEM (HRTEM) image (Fig. 8) confirms that the assynthesized nanowires are tetragonal $\mathrm{RuO}_{2}$ phase [22] with a single crystalline structure. The spacing between two adjacent planes is about $3.18 \AA$ (Fig. 8b), which is consistent with the lattice parameter expected for the (110) plane of the tetragonal phase of $\mathrm{RuO}_{2}$ (the theoretical value is $3.176 \AA$ ). The growth direction of the resulting nanowires is [1-10] in the given example, but we found no preferential orientation after analysis of a large number of nanowires. 


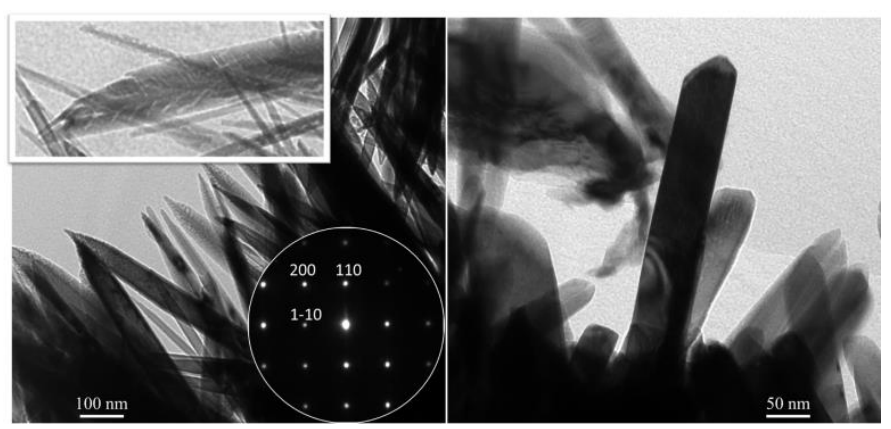

Fig. 7. Left: TEM image showing nanowires with plume shape. Inset: corresponding micro-diffraction pattern. Right: TEM image showing single and bi-crystal nanowires.

The elemental composition analysis of as-synthesized $\mathrm{RuO}_{2}$ nanowires (see supplemental materials 3 and 4) was determined by STEM-EDS (Scanning Transmission Electron Microscopy-Energy Dispersive Spectroscopy). Micro-EDS analysis is rarely very accurate because of the need to have a straight pathway of emerging X-rays to the detector. On a large set of nanowires, this technique shows that sodium is detected at low concentrations (about 2-5 at \%), which is also true for $\mathrm{KCl}$, its concentration varying from 1 to $3 \%$. Chlorine is not found because its corresponding signal is overlapped by ruthenium.

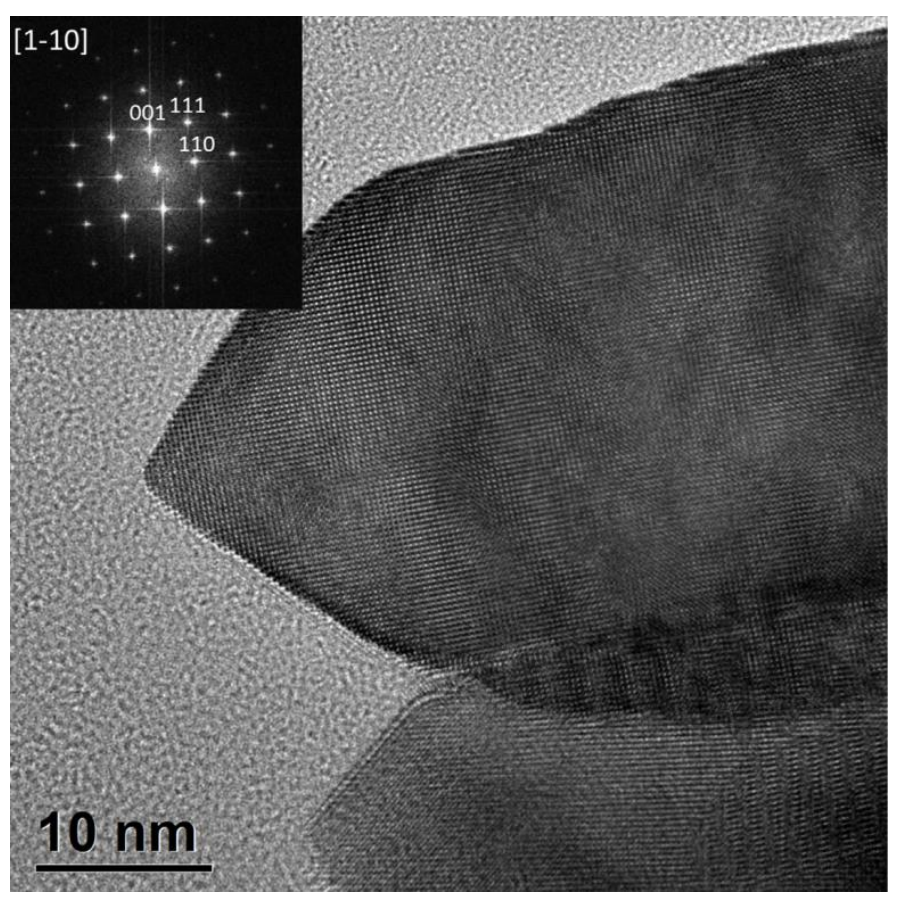

Fig. 8. High resolution image of a single-crystalline nanowire. Inset: Fourier transform analysis giving a spacing between two adjacent planes of $3.18 \AA$.

To better characterize the distribution of the alkali salt on a single nanowire, concentration profiles were recorded radially. Fig. 9 provides TEM micrographs of a single nanowire obtained in the presence of each alkali salt together with the radial distribution profile (over ten measure points) of the corresponding alkali element.
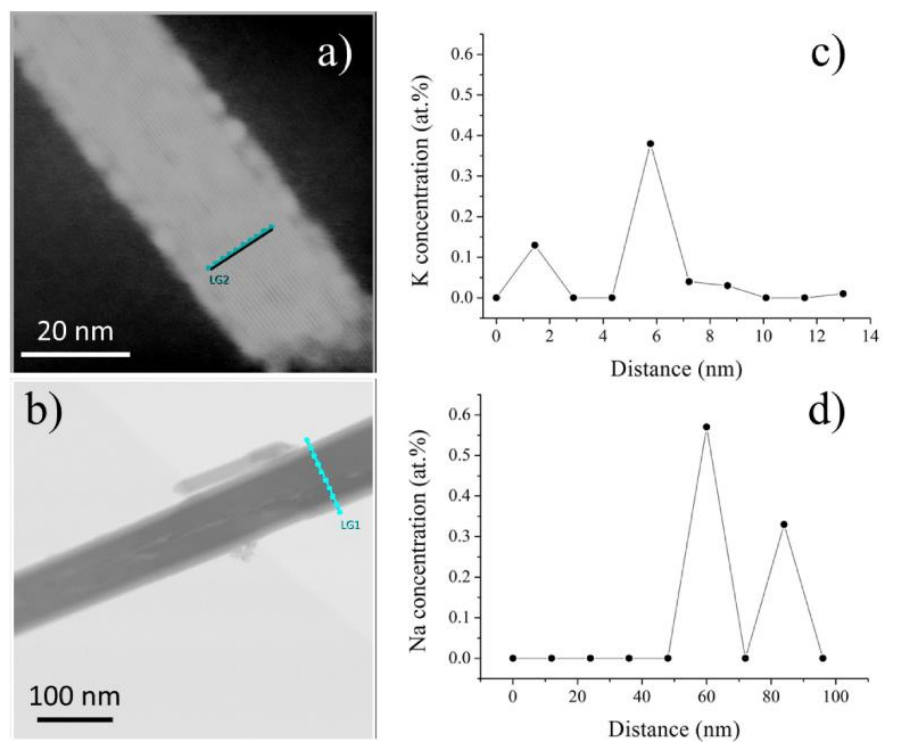

Fig. 9. a) TEM micrograph of a single nanowire obtained in the presence of $\mathrm{KCl}$. b) TEM micrograph of a single nanowire obtained in the presence of $\mathrm{NaCl}$. c) Radial distribution profile of corresponding potassium. d) Radial distribution profile of corresponding sodium.

From these profiles, it is clear that some parts of the nanowire do not contain any alkali element. Therefore, we infer that the alkali elements are distributed on the surface of the nanowire and not in its volume. Very likely, particles of $\mathrm{NaCl}$ or $\mathrm{KCl}$ get attached to the nanowire during its growth, leading to the weak concentration reported in our measures (see supplemental material 5). These analyses do not prove once and for all that alkali elements are not present in the core of the nanowire, but they clearly show that, if they are, their concentration is very limited. Since the presence of an alkali salt on nanowires has no measurable influence on the crystal lattice of ruthenium dioxide, this allows us to exclude the possible formation of eutectics. For sodium ruthenate phases, one finds: $\mathrm{NaRuO}_{2}$ [23], $\mathrm{NaRu}_{2} \mathrm{O}_{4}$ [24, 25], $\mathrm{NaRu}_{4} \mathrm{O}_{9}$ [26], $\mathrm{Na}_{2} \mathrm{RuO}_{3}$ [26, 27], $\mathrm{Na}_{2} \mathrm{RuO}_{4}$ [26, 27], $\mathrm{Na}_{2} \mathrm{Ru}_{4} \mathrm{O}_{9}$ [26], $\mathrm{Na}_{2} \mathrm{Ru}_{9} \mathrm{O}_{19}$ [26], $\mathrm{Na}_{3} \mathrm{Ru}_{4} \mathrm{O}_{9}$ [26, 28], $\mathrm{Na}_{4} \mathrm{RuO}_{4}$ [27], $\mathrm{Na}_{4} \mathrm{Ru}_{3} \mathrm{O}_{8}$ [27] and $\mathrm{Na}_{27} \mathrm{Ru}_{14} \mathrm{O}_{48}$ [29]. Beside, oxyhydrates can also form after air exposition, like $\mathrm{Na}_{\mathrm{x}} \mathrm{RuO}_{2}-\mathrm{yH}_{2} \mathrm{O}(\mathrm{x}=0.22, \mathrm{y}=0.45)$ [23].

In the case of $\mathrm{KCl}$, several potassium ruthenate phases are currently listed: $\mathrm{KRuO}_{4}$ [30], $\mathrm{KRu}_{4} \mathrm{O}_{8}$ [31], $\mathrm{K}_{1.5} \mathrm{Ru}_{8} \mathrm{O}_{16}$ [32], $\mathrm{K}_{2} \mathrm{RuO}_{3}$ [33], $\mathrm{K}_{2} \mathrm{RuO}_{4}$ [34] and $\mathrm{K}_{4} \mathrm{RuO}_{4}$ [33]. Like sodium ruthenates, oxyhydrates can be formed in humid air, like $\mathrm{K}_{0.2} \mathrm{RuO}_{2.1} \cdot \mathrm{nH}_{2} \mathrm{O}(\mathrm{n}=\sim 0,0.5,0.9)$ [35]. In every case, the concentrations of sodium and potassium in these phases are much higher than those measured experimentally.

\section{E. Nanowires growth mechanisms}

In order to try to monitor the nanowires growth obtained by oxidation of ruthenium substrate sprinkled with alkali salts, it is necessary to understand their possible growth mechanisms. In a previous work [18], we showed, in the same experimental conditions, that $\mathrm{RuO}_{2}$ nanowires could be grown without alkali salts, with similar growth rates. Then, sprinkling salt crystals on the ruthenium surface creates additional "nucleation sites". This technique is useful to localize the nanowire growth on the substrate at the specific spot where a grain is deposited. What is meant here by "nucleation site" is a local failure in the native $\mathrm{RuO}_{2}$ layer to make access to the underlying reservoir of ruthenium. We assume that this failure occurs thanks to the creation of triple point at the base of the 
grains. In order to verify this assumption, series of experiments were performed.

First, we substituted the alkali salts by gold islands which do not react with micro-afterglow plasma (no possible oxidation). The experimental procedure was as follow: a gold layer (about $50 \mathrm{~nm}$ ) is formed through the interstices of a TEM grid placed on the ruthenium substrate (Fig. 10a). When the grid is removed, two areas are observed: one masked by gold and one free of gold (Fig. 10b). The patterned surface is next oxidized by the micro-afterglow. In the area masked by gold, no nanostructure is found (Fig. 10c). In contrast, the gold-free area is characterized by a nanostructure made of lamellae with localized bundles of nanowires (Fig. 10d), as commonly observed on a ruthenium sample without any alkali salt. Therefore, gold is inert and does not catalyze the formation of nanowires. Due to this chemical inertness, gold does not allow to have nanowires at the edge of gold plots (no triple point) as with $\mathrm{NaCl}$ or $\mathrm{KCl}$.

Second, experiments were made by substituting $\mathrm{NaCl}$ and $\mathrm{KCl}$ by their homologous $\mathrm{NaI}$ and $\mathrm{KI}$ at the same concentrations. The experimental conditions were unchanged. It turns out that the growth of nanowires proceeds as with chlorine (see supplemental material 6). Nanowires are a bit shorter, maybe because of the lower reactivity of iodine with regard to chlorine, but the growth mechanism is basically unchanged.

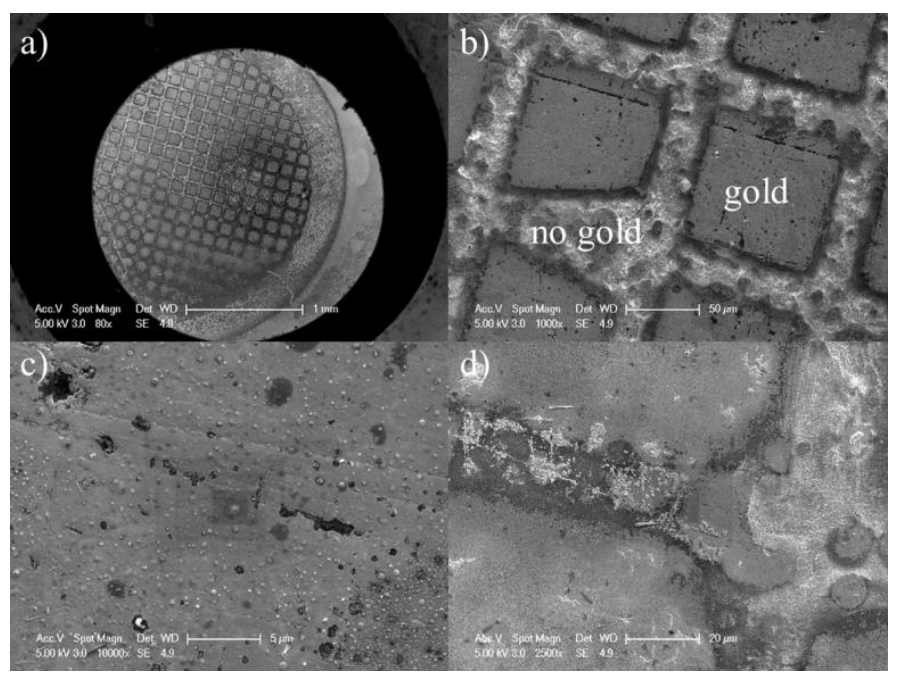

Fig. 10. a) Aspect of the surface after gold deposition through a mask. b) Magnification showing the patterned ruthenium substrate after microafterglow oxidation. c) Magnification of a gold area d) Sparse bundles of nanowires distributed along surface defects on a nanostructure made of $\mathrm{RuO}_{2}$ lamellae. No nanowires are observed on the edge of the gold plots.

Third, the role of water was checked. As the micro-afterglow is operated in air, because of the high reactivity of salts with water, we chose to introduce water on purpose to evaluate its role on the growth of nanostructures. In Fig. 11, SEM images of nanowires grown around $\mathrm{NaCl}$ grains for water flowrates in the range [0-1.33] sccm are depicted. The etching of the grains is all the more efficient as the flowrate of water increases. It is important to note that etching by water affects the whole grain, including the central part, whereas without water, only the edges are etched. The growth of the nanowires occurs at the base of the grains and it is not affected, as far as we can estimate it, by the partial pressure of water. The key point here is that the partial pressure of water coming from the surrounding air in the $\mathrm{Ar}-\mathrm{O}_{2}$ afterglow is negligible because no general etching occurs without water introduced on purpose. Then, $\mathrm{O}$ or $\mathrm{O}_{2}{ }^{*}$ are the active species that do control the growth of $\mathrm{RuO}_{2}$ nanowires. Moreover, direct reaction between $\mathrm{NaCl}$ or $\mathrm{KCl}$ with $\mathrm{O}$ or $\mathrm{O}_{2}{ }^{*}$ to produce $\mathrm{Na}_{2} \mathrm{O}$ or $\mathrm{K}_{2} \mathrm{O}$, whose melting points are about $1405 \mathrm{~K}$ and $1010 \mathrm{~K}$ respectively, are unlikely.
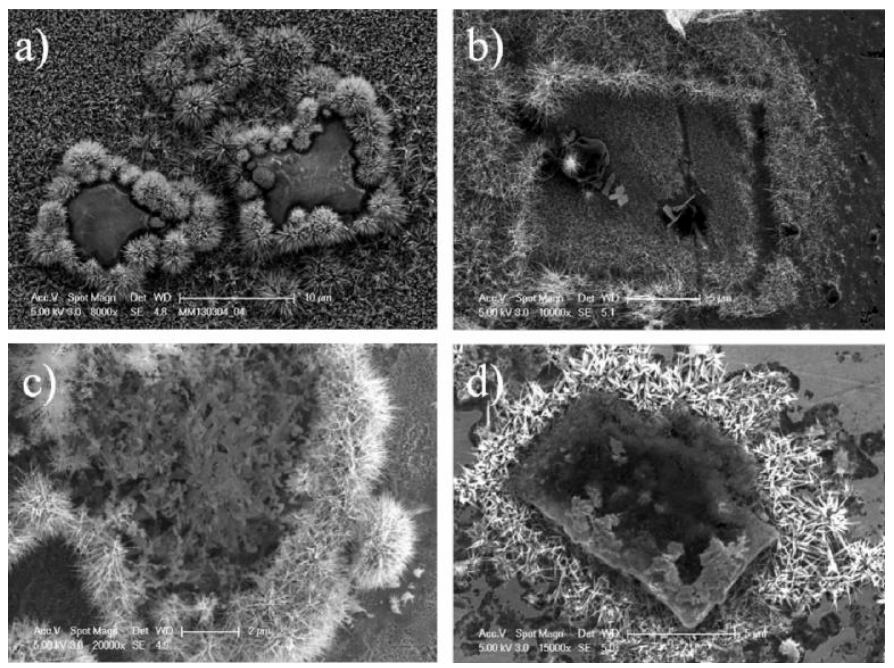

Fig. 11. Nanowires synthesized around $\mathrm{NaCl}$ grains with different flow rates of water injected in the discharge. a) $\mathrm{Q}_{\mathrm{H}_{2} \mathrm{O}}=0 \mathrm{sccm}$. b) $\mathrm{Q}_{\mathrm{H}_{2} \mathrm{O}}=0.33 \mathrm{sccm}$. c) $\mathrm{Q}_{\mathrm{H}_{2} \mathrm{O}}=0.66 \mathrm{sccm}$. d) $\mathrm{Q}_{\mathrm{H}_{2} \mathrm{O}}=1.33 \mathrm{sccm}$.

By looking at a sufficiently narrow spot where several similar grains are found, we can assume that the same conditions prevail, i.e. same concentration in active species and same temperature. In Fig. 12, we clearly notice that, although the conditions are the same, one $\mathrm{NaCl}$ grain behaves singularly.

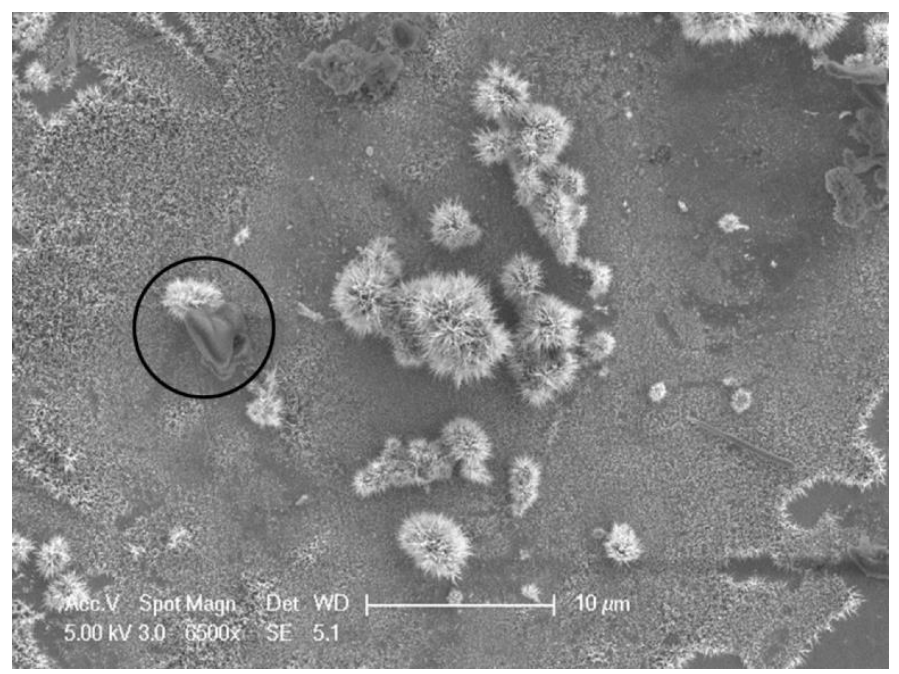

Fig. 12. SEM images of a selected area showing similar $\mathrm{NaCl}$ grains, one of which (circled in black) behaving singularly.

We infer from this observation that the nanowire growth is only possible if the alkali grain forms micro-cracks through the $\mathrm{RuO}_{2}$ passive layer that opens access to ruthenium from the underlying reservoir.

In Fig. 13a, the nanowire density is observed to be maximal at about $1 \mu \mathrm{m}$ from the edge. The presence of corrosion pits between the wall of the grain and the nanowires is noteworthy (Fig. 13b). These corrosion pits are also found with iodides (see supplemental material 7). As explained hereafter, these pits are the results of the nanowire growth and not the origin. 


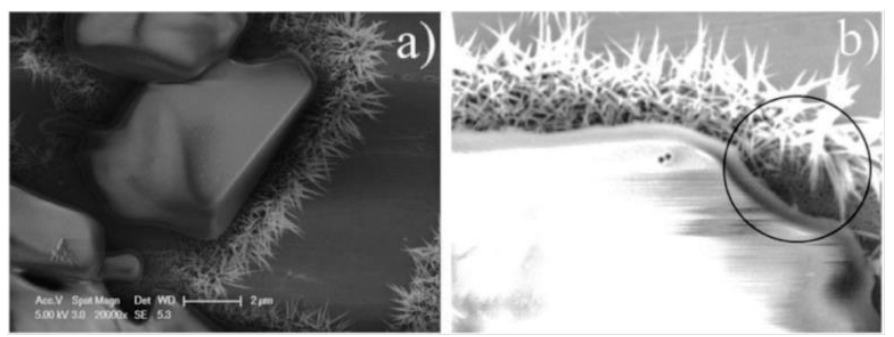

Fig. 13. Nanowires growing along the edge of a grain. The nanowire density is maximal at about $1 \mu \mathrm{m}$ from the edge. b) Magnification showing the presence of corrosion pits.

Alkali salt grains can adopt specific shapes with thickness gradients. This happens when evaporation makes the water droplet, loaded in alkali salt, flow. In Fig. 14a, an example of such a $\mathrm{NaCl}$ grain with thickness gradient is given. After treatment, we notice that nanowires grow over the grain along specific directions indicated by arrows in Fig. 14b. If we zoom in (Figs. 14c and 14d), we observe that nanowires progress inward by forming juxtaposed bundles of nanowires that are smaller if they have just been formed. We also observe that this stepwise progression - which must not be confused with the formation of concentric rings outward - also occurs along grain edges (circle area in Fig. 14b). From these observations, it seems likely that the inward propagation process is limited by surface diffusion. Besides, a nucleation step seems required to form, on an activated site, a new bundle of nanowires.

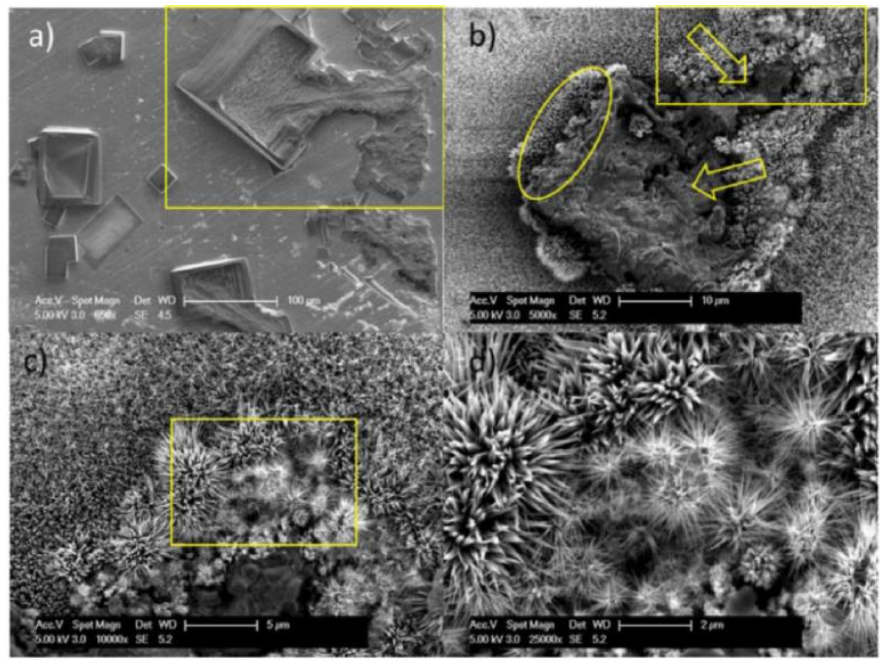

Fig. 14. a) Example of a $\mathrm{NaCl}$ grain with thickness gradient before treatment. b) Example of a $\mathrm{NaCl}$ grain with thickness gradient after oxidation by micro-afterglow. Arrows show the growth direction. The circled area shows bundles along a grain wall. c) Magnification of the yellow frame in figure b). d) magnification of the yellow frame in figure $\mathrm{c}$ ). $t=2 \mathrm{~h}$ $[\mathrm{NaCl}]=0.08 \mathrm{~g} \cdot \mathrm{mL}^{-1}$.

We can now draw a general picture of the formation of nanowires. The growth of nanowires near alkali salt grains is associated with the existence of a triple point where the alkali chloride or iodide, the ruthenium dioxide and active oxygen are present simultaneously. Contrary to nanowire bundles growing from emerging defects on surface that are not covered by alkali salt, the formation of nanowire along the edges of grains is linked to a localized corrosion process based on the synthesis of a gaseous mediator. Indeed, this mechanism no longer operates with gold but does with iodides.
To explain the corrosion mechanism, we have to assume that reaction (1) is replaced by another one where $\mathrm{NaCl}$ (or $\mathrm{KCl}$ ) is present.

$$
\mathrm{Ru}^{4+}+4 \mathrm{NaCl} \rightarrow \mathrm{RuCl}_{4}+4 \mathrm{Na}^{+}
$$

No thermodynamic data is available about this process to the best of our knowledge. Even the enthalpy of formation of $\mathrm{RuCl}_{4}$ is unknown. If this process does occur, the possibility of a chemical vapor deposition process comes up.

$$
\mathrm{RuCl}_{4}+\left(2 \mathrm{O} \text { or } \mathrm{O}_{2} *\right) \rightarrow \mathrm{RuO}_{2}+2 \mathrm{Cl}_{2}
$$

However, such a process seems unlikely for it leads to nanowires only by Vapor-Liquid-Solid or by self-catalysis like with $\mathrm{ZnO}$ [36], Si and $\mathrm{Ga}$ [37], GaN [38], SiC [39], etc. In the former process, a catalyst is needed, which is not observed here, whereas in the latter, it would not explain the stepwise behavior of the propagation process.

Reactions (1) and (2) cannot occur simultaneously but they can occur successively. Indeed, the growth process of a nanowire assumes the transportation of a metallic ion over several tens of micrometers before reaction (1) occurs. The propagation process is then limited by chemical reaction and not by diffusion, which is due to the low synthesis temperature. Then, $\mathrm{Ru}^{4+}$ ions attack sodium chloride first and transform $\mathrm{NaCl}$ into $\mathrm{Na}^{+}$. The synthesis of the oxide from $\mathrm{Na}^{+}$ would read:

$$
2 \mathrm{Na}^{+}+2 \mathrm{e}^{-}+\mathrm{O} \rightarrow \mathrm{Na}_{2} \mathrm{O}
$$

Islands of sodium oxide can form and, without chlorine, reaction (1) will be once again possible.

Thus, the formation of nanowires at the edge of grains is likely due to the presence of micro-cracks induced by that mechanical stress that breaks the continuity between the grain and the thin film of salt in the vicinity of the grain. The breakage could be easily induced by the difference of the expansion coefficients of $\mathrm{Ru}$ and $\mathrm{NaCl}$ or $\mathrm{KCl}$. Indeed, these coefficients are, at $300 \mathrm{~K}, 6.4 \times 10^{-6} \mathrm{~K}^{-1}$ and $40 \times 10^{-6} \mathrm{~K}^{-1}$ for $\mathrm{NaCl}$ or $36 \times 10^{-6} \mathrm{~K}^{-1}$ for $\mathrm{KCl}$, i.e. about a factor of 6 between both values.

The above set of reactions, which explains the possible growth mechanism for alkali metal-assisted growth of $\mathrm{RuO}_{2}$ at triple point, is summarized by Fig. 15. Each grain is deposited as a crystal on the passivated ruthenium substrate (step a in Fig. 15). When the plasma is turned on, thanks to thermal gradients, cracks open at the edge of grains, enabling the outward diffusion of ruthenium ions (step b). Then, the nanowires start growing (step c). The succession of chemical reactions (reactions 2, 4 and 1) at the surface of the alkali salt permits a progressive inward propagation of the nanostructure over the grain (step d). This step is accompanied by a depletion of the alkali salt that is consumed as time passes. We assume at this stage that surface transport and reactivity of the released ions, which depend on the local conditions prevailing around each grains, might play a role on the growth kinetics of the wires. However, no such information is available yet and this will be investigated in forthcoming works. The outward propagation that forms concentric circles around the grain is due to the formation of the defects by stress (step e), as explained in a former work of ours [18, 20]. Vacancies accumulate in ruthenium, forming Kirkendall porosity and leading to a self-limitation of the process. 


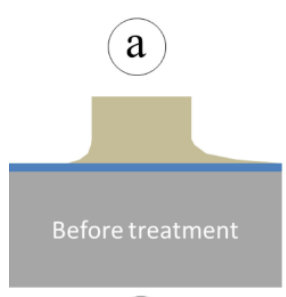

d

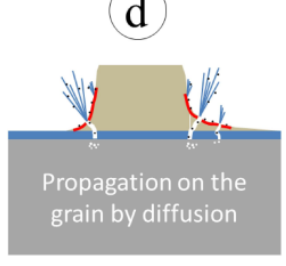

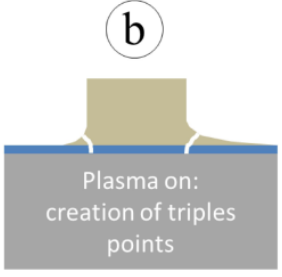

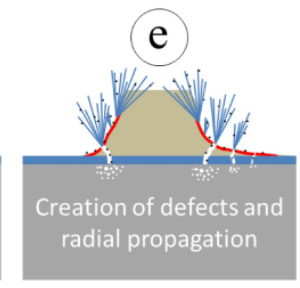

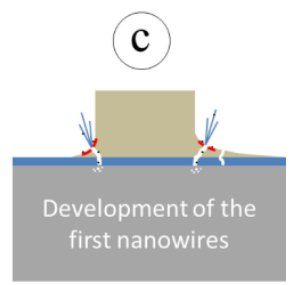

$\mathrm{Ru}^{4+}$

$\mathrm{Na}_{2} \mathrm{O}$

Grain of $\mathrm{NaCl}$

Oxide layer

Ruthenium

Vacancies
Fig. 15. Simplified mechanism of nanowire growth around the grains of alkali chloride. $\mathrm{NaCl}$ is taken as example, the mechanism applying to $\mathrm{KCl}$ too.

This growth mechanism is very different from the mechanism proposed by Kumar et al. [21] because of the low temperatures of the micro-afterglow compared with direct plasma $(T \sim 1300 \mathrm{~K}[8]$ vs $T<600 \mathrm{~K}[18])$. The role played by alkali salts is then more "mechanical" than "chemical" in our conditions.

\section{CONCLUSION}

We proposed an original process to grow ruthenium oxide nanowires (by alkali-assisted oxidation). The presence of salt grains enhances the growth of the nanowires all around them, creating a circular area where nanowires are found. Their average length decreases radially, from the grain outward. XRD, HRTEM and FFT analysis confirmed that the assynthesized nanowires are tetragonal $\mathrm{RuO}_{2}$ phase. They grow typically at temperature $\sim 570 \mathrm{~K}$. The growth mechanism of nanowires occurs at the triple point created around the grains (where there coexist $\mathrm{NaCl}, \mathrm{Ru}$ and oxidizing gaseous specie) and this was verified by substituting on one hand $\mathrm{NaCl}$ or $\mathrm{KCl}$ by gold which does not react with microwave afterglow plasma and on other hand by $\mathrm{NaI}$ or $\mathrm{KI}$ grains which are generally less reactive than $\mathrm{NaCl}$ or $\mathrm{KCl}$. This technique could be useful to localize the growth of nanowires along specific lines forming complex patterns and drawn by edges of grains with shapes that would be made on-demand.

\section{ACKNOWLEDMENT}

The "Service de Coopération et d'Action Culturelle" of the French embassy in Cameroon is gratefully acknowledged for the PhD grant of D. Kuete Saa.

\section{REFERENCES}

[1] Z. Chen, U. Cvelbar, M. Mozetič, J. He, and M. K. Sunkara, "Long-Range ordering of oxygen-vacancy planes in $\alpha-\mathrm{Fe}_{2} \mathrm{O}_{3}$ nanowires and nanobelts," Chem. Mater., vol. 20, no. 9, pp. 3224-3228, Apr. 2008.

[2] M. Mozetic, U. Cvelbar, S. Vaddiraju, and M.K. Sunkara, "A method for the rapid synthesis of large quantities of metal oxide nanowires at low temperatures," $A d v$. Mater., vol. 17, no. 17, pp. 2138-2142, July 2005.

[3] U. Cvelbar, Z. Q. Chen, M. K. Sunkara, and M. Mozetic, "Spontaneous Growth of Superstructure $\alpha-\mathrm{Fe}_{2} \mathrm{O}_{3}$ Nanowire and Nanobelt Arrays in Reactive Oxygen Plasma," Small, vol. 4, no.10, pp. 1610-1614, sept. 2008.

[4] U. Cvelbar, K. Ostrikov, I. Levchenko, M. Mozetic, and M. K. Sunkara, "Control of morphology and nucleation density of iron oxide nanostructures by electric conditions on iron surfaces exposed to reactive oxygen plasmas," Appl. Phys. Lett., vol. 94, no. 21, pp. 211502:1-211502:3, may 2009.

[5] K. Ostrikov, I. Levchenko, U. Cvelbar, M. Sunkara, and M Mozetic, "From nucleation to nanowires: a single-step process in reactive plasmas," Nanoscale, vol. 2, no. 10, pp. 2012-2027, Aug. 2010.

[6] K. Ostrikov, "Surface science of plasma exposed surfaces: A challenge for applied plasma science," Vacuum, vol. 83, no. 1, pp. 4-10, Sept. 2008.

[7] M. K. Sunkara, "Scalable production of nanowire arrays and powders using plasmas", In $223^{\text {rd }}$ ECS Meeting, Toronto, Canada, May 12-17, 2013, pp.761.

[8] A. K. Thapa, T. Nguyen, V. Vendra, G. Sunkara, and M. K. Sunkara, "Large scale production of titanate and tin oxide nanowire powders and arrays for anodes" in Meeting Abstracts, Honolulu PRiME 2012, The Electrochemical Society, vol. 10, pp. 889.

[9] V. Vendra, A. Thapa, S. Sunkara, T. N. Nguyen, and M. K. Sunkara, "Production of Manganese Oxide Nanowire Powders and Their Characterization for Li Ion Batteries and Capacitors" in Meeting Abstracts, Honolulu PRiME 2012, The Electrochemical Society, vol. 10, pp. 841.

[10] M. K. Sunkara, V. Kumar, J. H. Kim, and E. L. Clark, "Methods for synthesizing metal oxide nanowires", U.S. Patent No. 20,130,017,145. Washington, DC: U.S. Patent and Trademark Office, Jan. 17, 2013.

[11] C. C. Hu, K. H. Chang, M. C. Lin, and Y. T. Wu, "Design and tailoring of the nanotubular arrayed architecture of hydrous $\mathrm{RuO}_{2}$ for next generation supercapacitors," Nano Lett., vol. 6, no. 12, pp 2690-2695, Nov. 2006.

[12] J. H. Park, J. M. Ko, and O. O. Park, "Carbon nanotube $/ \mathrm{RuO}_{2}$ nanocomposite electrodes for supercapacitors", J. Electrochem. Soc., vol. 150, no. 7, pp A864-A867, May 2003.

[13] M. Min, K. Machida, J. H. Jang, and K. Naoi, "Hydrous $\mathrm{RuO}_{2} /$ carbon black nanocomposites with 3D porous structure by novel incipient wetness method for supercapacitors", J. Electrochem. Soc., vol. 153, no. 2, pp A334-A338, Dec. 2006.

[14] G. Arnoult, R. P. Cardoso, T. Belmonte, and G. Henrion, "Flow transition in a small scale microwave plasma jet at atmospheric pressure", Appl. Phys. Lett., vol. 93, no. 19, pp 191507:1-191507:3, Nov. 2008.

[15] D. Music, J. Breunung, S. Mráz, and J. M. Schneider, "Role of $\mathrm{RuO}_{3}$ for the formation of $\mathrm{RuO}_{2}$ nanorods", Appl. Phys. Lett., vol. 100, no. 3, pp 033108:1-033108:4, Jan. 2012

[16] Y.-T. Lin, C.-Y. Chen, C.-P. Hsiung, K.-W. Cheng, and J.-Y. Gan, "Growth of $\mathrm{RuO}_{2}$ nanorods in reactive sputtering”, Appl. Phys. Lett., vol. 89, no. 6, pp 063123:1-063123:3, Aug. 2006.

[17] C. C. Hsu, J. W.Coburn, D. B. Graves, "Etching of ruthenium coatings in O-2-and Cl-2-containing plasmas", J. Vac. Sci. Technol. A, vol. 24, no. 1, pp. 1-8, Jan./Feb. 2006.

[18] D. Kuete Saa, R.P. Cardoso, F. Kosior, A. Al Taweel, T. Gries, S. Laminsi, and T. Belmonte, "Growth of ruthenium dioxide nanostructures by micro-afterglow oxidation at atmospheric pressure", Surf. Coat .Technol., vol. 255, pp. 3-7, Sept. 2014.

[19] H. Over, "Ruthenium dioxide, a fascinating material for atomic scale surface chemistry", Appl. Phys. A, vol. 75, no. 1, pp. 37-44, Apr. 2002. 
[20] G. Arnoult, T. Gries, G. Henrion, S. Migot, V. Fournée, and T. Belmonte, "Localized Growth of Silicon Oxide Nanowires by Micro-Afterglow Oxidation", Plasma Process. Polym., vol. 9, no. 11-12, pp. 1125-1131, Dec. 2012

[21] V. Kumar, J. H. Kim, J. B. Jasinski, E. L. Clark, and M. K. Sunkara, "Alkali-Assisted, Atmospheric Plasma Production of Titania Nanowire Powders and Arrays", Cryst. Growth Des., vol. 11, no. 7, pp. 2913-2919, May 2011.

[22] C. E. Boman, "Refinement of the crystal structure of ruthenium dioxide", Acta Chem. Scand., vol. 24, no. 1, pp. 116-122, 1970.

[23] M. Shikano, C. Delmas, and J. Darriet, " $\mathrm{NaRuO}_{2}$ and $\mathrm{Na}_{x} \mathrm{RuO}_{2} \cdot \mathrm{yH}_{2} \mathrm{O}$ : New Oxide and Oxyhydrate with Two Dimensional $\mathrm{RuO}_{2}$ Layers", Inorg. Chem., vol. 43, no. 4, pp. 1214-1216, Nov. 2004.

[24] J. Darriet, "Structure cristalline de la phase type 'bronze de ruthénium' $\mathrm{Na}_{3}-\mathrm{xRu}_{4} \mathrm{O}_{9}$ ", Acta Crystallogr., vol. B30, no. 6, pp. 1459-1462, Feb. 1974.

[25] R. V. Panin, N. R. Khasanova, A. M. Abakumov, W. Schnelle, J. Hadermann, and E. V. Antipov, "Crystal structure and properties of the $\mathrm{Na}_{1}-\mathrm{xRu}_{2} \mathrm{O}_{4}$ phase", Russ. Chem. Bull. Int. Edition, vol. 55, no. 10, pp. 1717-1722, Oct. 2006.

[26] I. S. Shaplygin, and V. B. Lazarev, "New phases in a sodium-ruthenium-oxygen system", Russ. J. Inorg. Chem., vol. 25, no. 12, pp. 1837-1840, 1980.

[27] K. M. Mogare, K. Friese, W. Klein, and M. Jansen, "Syntheses and Crystal Structures of Two Sodium Ruthenates: $\mathrm{Na}_{2} \mathrm{RuO}_{4}$ and $\mathrm{Na}_{2} \mathrm{RuO}_{3}$ ", Z. Anorg. Allg. Chem., vol. 630, $\mathrm{n}^{\circ}$ 4, pp. 547-552, Apr. 2004.

[28] K. A. Regan, Q. Huang, M. Lee, A. P. Ramirez, and R. J. Cava, "Structure and magnetism of $\mathrm{NaRu}_{2} \mathrm{O}_{4}$ and $\mathrm{Na}_{2.7} \mathrm{Ru}_{4} \mathrm{O}_{9}$ ", J. Solid State Chem., vol. 179, no. 1, pp. 195-204, Jan. 2006

[29] J. M. Allred, L. M. Wang, P. Khalifah, and R. J. Cava, " $\mathrm{Na}_{27} \mathrm{Ru}_{14} \mathrm{O}_{48}$ : A new mixed-valence sodium ruthenate with magnetic heptameric plaquettes", J. Solid State Chem., vol. 184, no. 1, pp. 44-51, Jan. 2011.

[30] M. D. Silverman and H. A. Levy, "Crystal Structure of Potassium Perruthenate, $\mathrm{KRuO}_{4}{ }^{1,2}$,,$J$. Am. Chem. Soc., vol. 76, no. 12, pp. 3317-3319, Jun. 1954.

[31] M. Wilhelm and R. Hoppe, "Eine Neue Rutheniumbronze: $\mathrm{KRu}_{4} \mathrm{O}_{8}$ ", Z. Anorg. Allg. Chem., vol. 438, no. 1, pp. 90-96, Feb. 1978.

[32] F. Djafri, J. Canonne, F. Abraham, and D. Thomas, "Insertion du lithium dans la phase de structure hollandite: $\mathrm{KxRu}_{8} \mathrm{O}_{16}(\mathrm{x} \approx 1,5)$ " J. Less Common Metals, vol. 109, no. 2, pp. 323-329, Jul. 1985.

[33] M. I. Gadzhiev, and I. S. Shaplygin, "Reactions in the

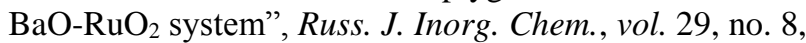
pp. 1230-1231, 1984.

[34] K. S. Kim, S. J. Kim, Y. H. Song, and C. S. Hahn, "Selective Oxidation of Allylic and Benzylic Alcohols Using Potassium Ruthenate $\left(\mathrm{K}_{2} \mathrm{RuO}_{4}\right)$ Under PhaseTransfer Catalysis Conditions", Synthesis, vol. 1987, no. 11, 1017-1018, 1987.

[35] K. Fukuda, H. Kato, J. Sato, W. Sugimoto, and Y. Takasu, "Swelling, intercalation, and exfoliation behavior of layered ruthenate derived from layered potassium ruthenate", J. Solid State Chem., vol. 182, no. 11, pp. 2997-3002, Nov. 2009.
[36] J.-J. Wu, and S.-C. Liu, "Catalyst-free growth and characterization of $\mathrm{ZnO}$ nanorods", J. Phys. Chem. B, vol. 106, no. 37, pp. 9546-9551, Aug. 2002.

[37] B.-S. Kim, T.-W. Koo, J.-H. Lee, D. S. Kim, Y.C. Jung, W. Hwang, et al., "Catalyst-free Growth of SingleCrystal Silicon and Germanium Nanowires", Nano Lett., vol. 9, no. 2, pp. 864-869, Jan. 2009.

[38] C. Chèze, L. Geelhaar, O. Brandt, W. M. Weber, H. Riechert, S. Münch, et al., "Direct comparison of catalyst-free and catalyst-induced GaN nanowires", Nano Res., vol. 3, no. 7, pp. 528-536, Jul. 2010.

[39] G. Z. Yang, H. Cui, Y. Sun, L. Gong, J. Chen, D. Jiang et al., "Simple catalyst-free method to the synthesis of $\beta$ $\mathrm{SiC}$ nanowires and their field emission properties", $J$. Phys. Chem. C, vol. 113, no. 36, pp. 15969-15973, Aug. 2009.

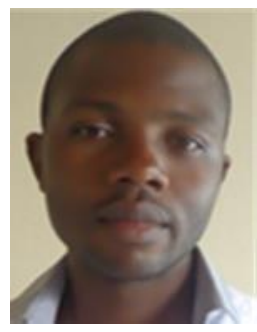

Duclair KUETE SAA is a Ph.D holder in both of Materials Sciences (University of Lorraine, France) and Inorganic Chemistry (University of Yaoundé 1, Cameroon) since June 2015. He worked on "Synthesis of nanostructures of ruthenium dioxide by microwave afterglow at atmospheric pressure." thanks to a grant that he obtained from the French Embassy in Cameroon. He also holds his MSc (2010) in Materials Chemistry from the University of Yaoundé 1. Since July 2015, he is a Research Associate in the plasma group of the Faculty of Science, University of Yaoundé 1. His current research interests includes plasma synthesis of oxide nanostructures/nanocomposites (for catalysis and

supercapacitors), plasma treatment of solid surface and plasma treatment of waste water. Dr. KUETE SAA is the author/coauthor of five original research papers in the areas of thin films, nanostructures/nanocomposites and waste water treatment. He also attended international conferences in which he made poster and oral presentations.

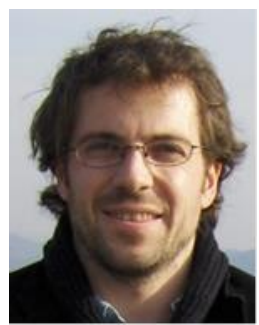

Thomas Gries received the MS degree in plasma physics from the University of Nancy (France) in 2004 and the PhD degree in material science from the University of Orléans (France) in 2008. He was a postdoctoral fellow at Saarland University (Germany) before joining the Institut Jean Lamour, Nancy (France) as CNRS researcher in 2010. His main investigations are focused on atmospheric pressure plasmas and their applications in the synthesis of nanostructured materials. He is a co-author in 33 publications and 2 patents. He has also participated to 71 communications in conferences and 10 invited lectures.

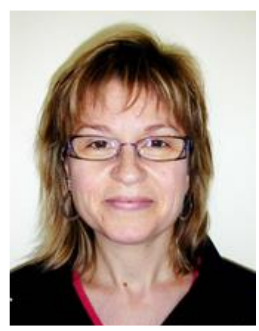

S. Migot was born in 1968. She obtained a Master in materials science in 1993. After, she worked during 21 years as technician at the University of Lorraine. She prepared samples and characterized them by X-Ray (Laue, Berg-Barret and Lang), optical microscopy, scanning electron microscopy (with EDS, EBSD) and transmission electron microscopy (with EDS). Now she is Engineer of the CNRS and she is 
responsible for two devices at the Institute Jean Lamour: TEM Philips CM200 and SEM-FIB Helios Nanolab 600i. She is the co-author of 30 papers.

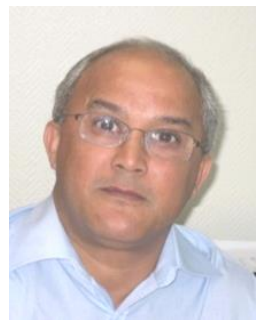

Dr. Jaafar Ghanbaja was born in Agadir (Marrocco) in 1958. He completed a PhD on the synthesis of doped polymers by alkali metals in Nancy, University of Lorraine (France). After being a physics teacher at high school, since 1990, he was responsible of several services of electron microscopy at the University of Lorraine. $\mathrm{He}$ is a high-level specialist of high transmission electron microscopy (TEM) regarding both practical utilization (including sample preparation) and scientific analysis of several materials especially carbon nanomaterials. He is an expert in electronic imaging (STEM), electronic diffraction and electronic analysis such as EELS and EDS. He is presently an ENGINEER in the Institute Jean Lamour where he is the head of the microscopy platform composed of tens of microscopes (FIB, MET, SEM). He coauthored 194 publications in high-level international peerreviewed journals including 2 papers published in Nature, his $\mathrm{H}$-index is of 31 .

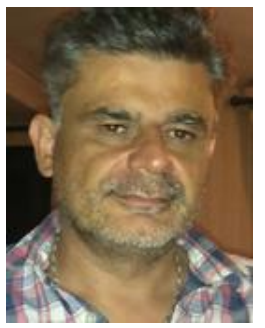

Pascal Boulet did his $\mathrm{PhD}$ in Solid State Chemisty, in the frame of the European program "Human Capability and Mobility". He performed his thesis work in the network composed of 4 different labs: Institut für Physikalische Chemie in Vienna(A), Dipartimento di Chimica e Chimica Industrial in Genova (I), the NCSR of Demokritos in Athens (GR) and the institut des Sciences Chimiques de Rennes (F). In 1999, after one year in Vienna as a post doc, he joined for 6 years, the Institut for Transuranium elements (EC-JRC) in Karlsruhe(G). In 2006, he spent 6 months at the synchrotron ANKA in Karlsruhe on the Institute for Nuclear Waste Disposal (INE) beamline, and got a permanent position in the CNRS at the Institut Jean Lamour in Nancy. He is in charge of a plateform called "centre de compétences XGamma" dealing for all X-ray and Mossbauer spectroscopy facilities for the institute. His research is shared between 3 different fields i) to look for new intermetallic phases showing interesting properties like magnetic ordering or superconductivity ii) to look for new quasicrystalline and approximant phases with rare earth, iii) and characterization of thin film by XRD. He is co-author of more than 100 papers in refereed international journals and in proceeding of international conferences.

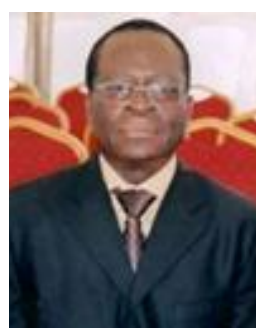

Samuel Laminsi, Ph.D is the head of plasma chemistry of environment and materials team. He received his doctorate (3rd Cycle) in Inorganic Chemistry in 1989 from the University of Yaounde. He became Professor/Researcher at the University of Yaounde 1 since 1991. He also holds his Ph.D (2005) in Inorganic Chemistry from the University of Yaounde 1 and was promoted to full Professorship in 2015. Since 2009 he $\mathrm{He}$ is the Director of Laboratory of Mineral Chemistry, Department of Inorganic Chemistry, Faculty of Science. Samuel Laminsi is the author/co-author of over 40 original research papers $\mathrm{He}$ also presented both orals and posters communications in international conferences Samuel's research interests include Plasma synthesis of metal oxides (nanostructures and nanocomposites) and plasma treatment of waste water. He serves as a regular reviewer for numerous journals including Plasma Chemistry and Plasma Processing, Journal of Nanoscience and Nanotechnology, Environmental Monitoring and Assessment...

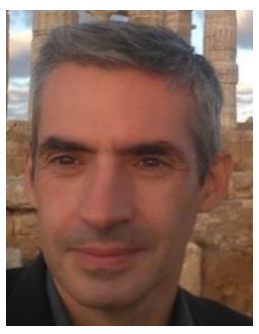

Thierry Belmonte is senior scientist at the Institut Jean Lamour, Nancy, France. He is an engineer who studied in Grenoble and obtained his $\mathrm{PhD}$ in material science in 1993. He became researcher of the CNRS the same year and was promoted Research Director in 2006. From 2009 to 2012, he managed the Institut Jean Lamour as deputy-director. $\mathrm{He}$ is member of the French's National Vacuum Society and Physical Society. Thierry Belmonte's research is mainly devoted to plasma nanoscience and, more recently, to plasmas in liquids. He published 202 papers, presented 323 posters or oral communications in conferences, 67 invited lectures, wrote 7 chapters in books and 6 patents. He was awarded the bronze medal of the CNRS and the first price of the Region Lorraine. 